\title{
A Systematic Review of Literature Reporting on Studies Analysing Technologies for Ageing in Place to Support Community-Dwelling Older Adults
}

\author{
Alexandra Queirós ${ }^{1 *}$, Milton Santos ${ }^{1}$, Margarida Cerqueira ${ }^{2}$, Nelson Pacheco Rocha ${ }^{3}$ \\ ${ }^{1}$ Health Sciences School, IEETA, University of Aveiro, Aveiro, PORTUGAL \\ ${ }^{2}$ Health Sciences School, University of Aveiro, Aveiro, PORTUGAL \\ ${ }^{3}$ Department of Medical Sciences, IEETA, University of Aveiro, Aveiro, PORTUGAL
}

\section{*Corresponding Author: alexandra@ua.pt}

Citation: Queirós, A., Santos, M., Cerqueira, M. and Rocha, N.P. (2017). A Systematic Review of Literature Reporting on Studies Analysing Technologies for Ageing in Place to Support Community-Dwelling Older Adults. Journal of Information Systems Engineering \& Management, 2(3), 17. doi: 10.20897/jisem.201717

Published: August 2, 2017

\begin{abstract}
The present article reports a systematic review of reviews and meta-analysis whose main objective was to systematize current evidence of technologies for ageing in place designed to support the daily living of community-dwelling older adults. The broad analysis of the study reported in the present article is useful to inform older adults, practitioners and researchers about the state of the art of technologies for ageing in place. A total of 24 reviews and meta-analysis were retrieved. These studies analyse the impact of different technologies in community-dwelling older adults, considering several outcomes, namely physical activity, nutrition, health education, or loneliness and social isolation.
\end{abstract}

Keywords: technologies for ageing in place, older adults

\section{INTRODUCTION}

The inclusion of older people in the community through dynamic participation is the active ageing concept's central issue, taking into consideration an optimised process requiring social participation within the family, peers and community, with health and security. This conception combines five others (Garcia et al., 2016; Kruse, 2012; Salvador-Corulla and Gasca, 2010; WHO, 2004): i) quality of life and well-being (physical, social and mental; subcategory of quality of life), ii) health (influenced by personal and environmental factors and related to functionality), iii) independence (ability to perform daily physical activities with little or no help), iv) autonomy (ability to make decisions in daily live), and v) productivity and creativity. Active ageing thus takes into account people's desire to remain in their own home with quality of life, even if suffering physical and/or cognitive health decline, with adequate protection in terms of safety and health care.

In this context, technologies for ageing in place (Pastalan, 1990; Connelly, Mokhtari and Falk, 2014; Normie, 2011) are important facilitators. This study is part of a medium-term project that aims to systematize current evidence of technologies for ageing in place (Queirós, Pereira, Dias and Rocha, 2017; Queirós, Pereira, Santos and Rocha, 2017; Queirós, Santos, Cerqueira and Rocha, 2017) and its main goal was to report technological solutions to support community-dwelling older adults. Particularly, the study presented in this article complements other reviews of reviews and meta-analysis reported in the literature focusing on technological solutions tailored for specific pathologies (e.g. diabetes, congestive heart failure, chronic obstructive pulmonary disease cancer or mental conditions).

In addition to this section (Introduction), the paper comprises four more sections: Related Work, Methods, Results, and Discussion and Conclusion. 


\section{RELATED WORK}

Independently of the circumstances, the viability of ageing in place requires structural changes of the care systems (Pastalan, 1990). To accommodate the changing functional needs of older adults there is the need of personalized care, although the current models of the provision of health care services are based on scientifically optimized standard procedures oriented to diagnosis-based needs and centered on diseases (Rigby, 2012). The concept of personalized care can be understood as the individually customization of diagnosis and therapy (i.e. personalized medicine), but it can also mean the empowerment of the common citizens, allowing them to be actively evolved in their health and care pathway. This may contribute to the overall quality of the healthcare provision (e.g. rehabilitation, supportive and technical nursing care, domestic aid, personal care or support to informal caregivers). Equally imperative are the logistical support requirements and constraints of the care providers, whether formal or informal, that also affect the quality of the healthcare provision.

Information technologies have been recognized to be able to mitigate many of the complex practical challenges and to contribute to advanced care paradigms such as eHealth and related concepts, such as Medicine 2.0 (Eysenbach, 2008), connected health (Kvedar, Coye and Everett, 2014), or holistic health (Mori, Mazzeo, Mercurio and Verbicaro, 2013). The eHealth paradigm encompasses a wide range of seervices, including telemedicine, telecare, mHealth and ambient assisted living (AAL).

Although there is poor consistency in the various definitions reported by the literature, telemedicine has been defined as the delivering of clinical and educational services through the use of information technologies (Norris, 2001) and implies the use of technological solutions as part of the clinical decision-making process (Emery, Heyes and Cowan, 2002). In turn, telecare is related to technological solutions that enable patients to maintain their independence and safety while remaining in their own residential environments, including mobile monitoring devices, medical alert systems, and consumer technologies such as computers and telephones (Emery et al., 2002). Moreover, mHealth means the application of mobile communications to support the care provision (Boulos, Brewer, Karimkhani, Buller and Dellavalle, 2014; Davis, DiClemente and Prietula, 2016) and AAL is related to the application of the ambient intelligence (AmI) to enable older adults with specific demands to live longer in their natural environment (Camarinha-Matos and Afsarmanesh, 2011).

Considering the broad definition of eHealth, the literature reports applications to support home monitoring, as well as to promote the empowerment of the older adults and their informal caregivers, targeting the specificities of a wide range of chronic conditions, including diabetes, congestive heart failure, chronic obstructive pulmonary disease, cancer and mental conditions:

- Diabetes - eHealth applications might provide a variety of functions to support older adults with diabetes, both in terms of home monitoring, self-management or patient adherence (e.g. self-monitoring blood glucose recording, medication compliance, prandial insulin dose calculators, daily eating behaviours, physical activity and also integrated communication between patients and healthcare providers) (Baron, McBain and Newman, 2012; El-Gayar, Timsina, Nawar and Eid, 2013; Or and Tao, 2014; Garabedian, Ross-Degnan and Wharam, 2015), which impacts different outcomes: glycaemia by using glycosylated haemoglobin (HbA1c) as a proxy, physiological parameters (e.g. weight, depression, blood pressure, cholesterol level, triglycemius level, fluctuation index), health-related quality of life, behaviour outcomes (e.g. diet and healthy eating or physical activity) (El-Gayar et al., 2013; Garabedian et al., 2015; Arambepola et al., 2016; Farmer et al., 2016), patient self-motivation, patient-clinician communication, medication adherence, and structural outcomes related to care coordination (Or and Tao, 2014; Garabedian et al., 2015; Arambepola et al., 2016).

- Congestive heart failure - Automatic patient data transmission by means of monitoring devices is being used together with standard telephone calls to allow the assessment of symptoms and vital signs, as well as the transmission of automatic alarms (Conway, Inglis and Clark, 2014; Nakamura, Koga and Iseki, 2014) targeting older adults with congestive heart failure. Home monitoring is used mainly to minimize heart failure-related hospitalizations and all-cause mortality (Conway et al., 2014) when compared with usual care, but several secondary outcomes are also considered, such as self-care behaviour (e.g. adherence to prescribed medication, daily weighing or adherence to exercise recommendations).

- Chronic obstructive pulmonary disease - the literature reports applications to increase self-care behaviors (Lundell, Holmner, Rehn, Nyberg and Wadell, 2015; Pedone and Lelli, 2015) of older adults with chronic obstructive pulmonary disease. These applications are usually supported by a wide range of devices to measure and transmit different types of information (e.g. weight, temperature, blood pressure, oxygen saturation, spirometry parameters, symptoms, medication usage or steps in a 6-minutes walking distance). Furthermore, in some cases the automatic data acquisition is complemented by clinical staff using questionnaires in telephone interviews (Lundell et al., 2015) to assess several outcomes including, among others, health-related quality of life, patient satisfaction, or physical capacity and effects of dyspnoea (Lundell et al., 2015, Pedone and Lelli, 2015). 
- Cancer - The empowerment of patients with cancer can contribute to them being autonomous and respected, having knowledge, having psychosocial and behavioural skills, receiving support from community, family, and friends (Groen et al., 2015). In this respect, eHealth applications can support knowledge transmission, including electronic survivorship care plans, and patient-to-patient or patient-tocaregiver communication (Groen et al., 2015).

- Mental conditions - videoconference, computer-based and web-based applications are being used to support older adults with mental illness (e.g. psychosis, depression or dementia). The literature reports the effectiveness of different remote treatments and highlights participant satisfaction (Alvarez-Jimenez et al. 2014; García-Lizana and Muño-Mayorga, 2010; Highton-Williamson, Priebe and Giacco, 2015; Lazar, Thompson and Demiris, 2014; Richards and Richardson, 2012; Sharp, Kobak and Osman, 2011).

Although several reviews of reviews and meta-analysis related to technologies for ageing in place reported studies focusing on older adults with chronic diseases, there is a lack of systematized evidence of the state of the art research when looking for community-dwelling older adults without specific chronic conditions. Therefore, this systematic review of reviews and meta-analysis aimed to systematize current evidence of technologies for ageing in place designed to support the daily living of community-dwelling older adults.

\section{METHODS}

Considered the aforementioned objective, the study reported in this article analyse innovative technologies that have been used for aged care and was informed by the following research questions (RQ):

- RQ1: Which aspects of the daily living of community-dwelling older adults can be assisted by technologies for ageing in place?

- RQ2: What technologies for ageing in place have recently been used to assist community-dwelling older adults in their daily living?

- RQ3: What are the evidences of the adoption of technologies for ageing in place among community-dwelling older adults?

Since a large number of articles have been published, this study included systematic reviews or meta-analyses only.

An initial scoping study was conducted, and its outcomes were discussed and captured in a review protocol with explicit descriptions of the methods to be used and respective steps.

The resources considered to be searched were two general databases (Web of Science and Scopus) and two specific databases (PubMed, a medical-related database, and IEEE Explorer, a technological database).

The search queries were defined to include: i) all the reviews and meta-analysis where any of the keywords 'telecare', 'telemedicine', 'homecare', 'telehealth', 'telemonitoring', 'remote monitoring', 'telerehabilitation', 'ehealth', 'mobile health', 'mhealth', or 'assisted living' were present in the title or abstract; and ii) all the reviews and meta-analysis where any of the keywords 'information technology', 'information and communication', 'technology-based', 'internet-based', 'web-based', 'on-line', 'mobile phone', 'smartphones', 'mobile apps', 'monitoring devices', or 'consumer health information' were present in the title or abstract together with any of the keywords 'healthcare', 'health care', 'patient', or 'chronic condition'. The search queries, performed on $30^{\text {th }}$ April 2016, were limited to articles in English, but conducted in any country, and were intended to include reviews and meta-analysis published after 2006.

In terms of inclusion criteria, it was considered the inclusion of reviews and meta-analysis related to technological solutions that can be used to support daily living of community-dwelling older adults.

Considering the exclusion criteria, the authors aimed to exclude articles related to the support of older adults with chronic diseases (e.g. diabetes, chronic obstructive pulmonary disease or congestive heart failure), including home monitoring. Furthermore, the authors also removed articles that have one of the following exclusion criteria: i) articles that were in other languages than English; ii) articles reporting systematic reviews of reviews; iii) articles that do not target community-dwelling older adults, including articles that target exclusively the formal and informal caregivers; iv) articles reporting applications that were designed to be used in an institutional environment and not in older adults' domicile; and v) articles that are not relevant for the objective of this study.

After the removal of duplicates and articles not published in English, the selection of the remainder articles was performed by two authors in three steps: i) first, the authors assessed all titles for relevance and those clearly not meeting the inclusion criteria were removed; ii) afterwards, the abstracts of the retrieved articles were assessed against the inclusion and exclusion criteria, and several articles were removed; and iii) lastly, the authors assessed the full text of the remainder articles according to the outlined inclusion and exclusion criteria. In all these three steps, any disagreement between the authors was discussed and resolved by consensus. 


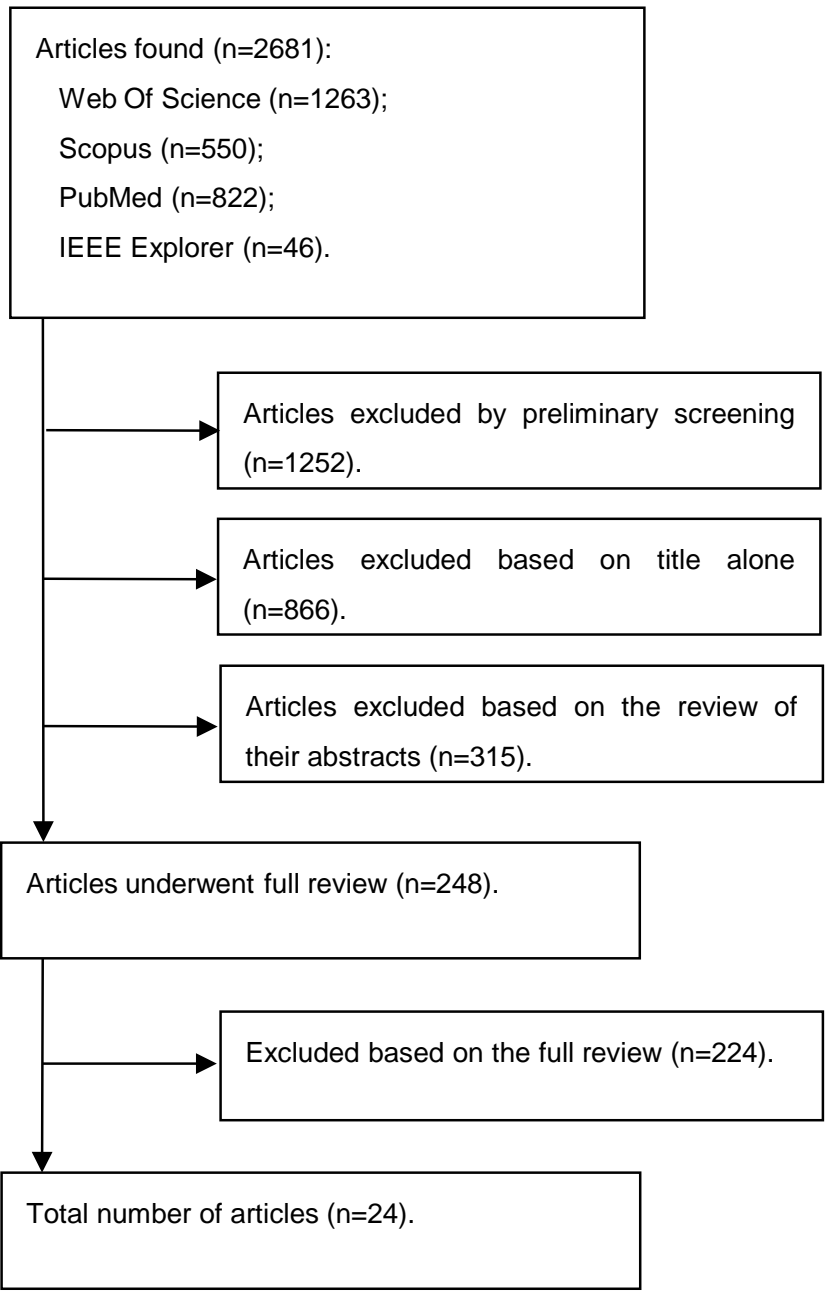

Figure 1. Review flowchart

In the data extraction stage, for every one of the selected articles, the following information was registered in a data sheet prepared by the authors: i) demographics of the published work (i.e. authors, year or source of publication); ii) scope of the review; iii) the quality assessment procedures used in the review; iv) details of the research methods of the primary studies included in the review; v) technologies being reported; vi) the problems being solved by these technologies; vii) the outcomes being measure; viii) evidence of the impact of the reported applications; and ix) recommendations for the future.

Finally, the main objective of the analysis stage was to answer the aforementioned research questions. The synthesis of the results was based on the process proposed by Ghapanchi and Aurum (2011). For instance, to classify the technologies for ageing in place reported, the synthesis process involved extracting the terms and definitions used in the included articles to create a primary list of technologies, which was then refined by further analyses in order to obtain the final list.

\section{RESULTS}

Figure 1 presents the flowchart of the systematic review done. A total of 2681 articles was retrieved from the initial search on PubMed (822 articles), Web of Science (1263 articles), Scopus (550 articles) and IEEE Explorer (46 articles). The initial screening yielded 1429 articles by removing the duplicates or the articles without abstracts (1252 articles). After exclusions based on title alone (866 articles) 563 articles were retrieved. Afterwards, 315 articles were eliminated based upon review of their abstracts. The 248 remaining full texts articles were assessed against the inclusion and exclusion criteria and 224 articles were removed. The scope of the 24 final reviews considered is presented in Table 1.

The number of primary studies included in the reviews vary from nine (Kelders, Kok and Van Gemert-Pijnen, 2011; Vegting, Schrijver, Otten and Nanayakkara, 2014) to 457 (Bardus, Smith, Samaha and Abraham, 2015). The type and rigor of study designs varied: i) Five reviews (Fox, 2009; Kelders et al. 2011; Foster, Richards, Thorogood and Hillsdon, 2013; Mateo, Granado-Font, Ferré-Grau and Montaña-Carreras, 2015; Beishuizen et al., 2016) 
Journal of Information Systems Engineering \& Management, 2(3), 17

Table 1. Scope of the reviews

\begin{tabular}{|c|c|c|c|}
\hline \# & Year & Scope & RCT/N* \\
\hline $\begin{array}{l}\text { (Fry \& Neff, } \\
2009)\end{array}$ & 2009 & $\begin{array}{l}\text { Effectiveness of limited contact interventions based on periodic prompts and } \\
\text { targeting physical activity, dietary assessment and weight loss }\end{array}$ & $0 / 19$ \\
\hline $\begin{array}{l}\text { (Ngo et al., } \\
2009)\end{array}$ & 2009 & Impact of IT on dietary assessment & $0 / 14$ \\
\hline (Fox, 2009) & 2009 & Impact of interactive, computer-based education programs on patient education & $25 / 25$ \\
\hline $\begin{array}{l}\text { (Kelders et al. } \\
\text { 2011) }\end{array}$ & 2011 & Adherence to web-based interventions for weight control & $9 / 9$ \\
\hline $\begin{array}{l}\text { (Kennedy et al., } \\
\text { 2012) }\end{array}$ & 2012 & $\begin{array}{l}\text { Application of dynamic and adaptive information processing in behaviour } \\
\text { change interventions }\end{array}$ & $6 / 41$ \\
\hline $\begin{array}{l}\text { (Lieffers \& } \\
\text { Hanning, 2012) }\end{array}$ & 2012 & $\begin{array}{l}\text { Comparison of nutrition applications for mobile devices with conventional } \\
\text { methods }\end{array}$ & $0 / 18$ \\
\hline $\begin{array}{l}\text { (Bolle et al., } \\
\text { 2015) }\end{array}$ & 2012 & $\begin{array}{l}\text { Effects of mobile phone messaging interventions on health status and health } \\
\text { behaviour outcomes }\end{array}$ & $13 / 18$ \\
\hline $\begin{array}{l}\text { (Blackman et al. } \\
\text { 2013) }\end{array}$ & 2013 & $\begin{array}{l}\text { Inclusion of factors that inform generalizability across settings and populations } \\
\text { in the reports of mobile health interventions promoting physical activity }\end{array}$ & $14 / 15$ \\
\hline $\begin{array}{l}\text { (Geraedts et al., } \\
\text { 2013) }\end{array}$ & 2013 & $\begin{array}{l}\text { Effectiveness of remote feedback on physical activity in home-based } \\
\text { interventions for older adults with or without medical conditions }\end{array}$ & $27 / 32$ \\
\hline $\begin{array}{l}\text { (Buchholz et al., } \\
\text { 2013) }\end{array}$ & 2013 & Physical activity text messaging interventions & $5 / 10$ \\
\hline $\begin{array}{l}\text { (Foster et al., } \\
2013)\end{array}$ & 2013 & $\begin{array}{l}\text { Comparison of the effectiveness of online interventions for physical activity } \\
\text { promotion }\end{array}$ & $11 / 11$ \\
\hline $\begin{array}{l}\text { (Buhi et al. } \\
\text { 2013) }\end{array}$ & 2013 & Behavioural mobile health & $18 / 34$ \\
\hline $\begin{array}{l}\text { (Moorhead et } \\
\text { al., 2013) }\end{array}$ & 2013 & $\begin{array}{l}\text { Identification of the uses, benefits, and limitations of social media for health } \\
\text { communication among the general public, patients, and health professionals }\end{array}$ & $1 / 98$ \\
\hline $\begin{array}{l}\text { (Bort-Roig et al., } \\
\text { 2014) }\end{array}$ & 2014 & $\begin{array}{l}\text { Evidence on smartphones and their viability for measuring and influencing } \\
\text { physical activity }\end{array}$ & $0 / 26$ \\
\hline $\begin{array}{l}\text { (Vegting et al., } \\
\text { 2014) }\end{array}$ & 2014 & $\begin{array}{l}\text { Effects of Internet delivered multiple modifiable lifestyle interventions } \\
\text { complementary to usual care on cardiovascular risk factors }\end{array}$ & $9 / 9$ \\
\hline $\begin{array}{l}\text { (Hawley-Hague } \\
\text { et al., 2014) }\end{array}$ & 2014 & Older adults' perceptions of falls technologies & $1 / 20$ \\
\hline $\begin{array}{l}\text { (Mateo et al., } \\
\text { 2015) }\end{array}$ & 2015 & $\begin{array}{l}\text { Efficacy of mobile applications compared with other approaches to promote } \\
\text { weight loss and increase physical activity }\end{array}$ & $12 / 12$ \\
\hline $\begin{array}{l}\text { (Laranjo et al., } \\
\text { 2014) }\end{array}$ & 2015 & $\begin{array}{l}\text { Use and effectiveness of interventions using social networking sites to change } \\
\text { health behaviours }\end{array}$ & $8 / 12$ \\
\hline $\begin{array}{l}\text { (Bardus et al., } \\
\text { 2015) }\end{array}$ & 2015 & $\begin{array}{l}\text { Comprehensive map of the use of online applications for influencing behaviours } \\
\text { related to weight management }\end{array}$ & $0 / 457$ \\
\hline $\begin{array}{l}\text { (Bert et al., } \\
\text { 2014) }\end{array}$ & 2015 & $\begin{array}{l}\text { Effectiveness of online applications for older adults in terms of care knowledge, } \\
\text { self-management and health outcomes }\end{array}$ & $2 / 21$ \\
\hline $\begin{array}{l}\text { (Matthews et al., } \\
\text { 2016) }\end{array}$ & 2016 & $\begin{array}{l}\text { Mobile applications for health behavioural change, namely in terms of the } \\
\text { promotion of physical activity }\end{array}$ & $5 / 20$ \\
\hline $\begin{array}{l}\text { (Shingleton \& } \\
\text { Palfai, 2016) }\end{array}$ & 2016 & $\begin{array}{l}\text { Methods and efficacy of technology-delivered motivational interviewing } \\
\text { interventions. }\end{array}$ & $28 / 41$ \\
\hline $\begin{array}{l}\text { (Chen \& Schulz, } \\
\text { 2016) }\end{array}$ & 2016 & Effects of IT interventions on reducing social isolation of the elderly & $6 / 26$ \\
\hline $\begin{array}{l}\text { (Beishuizen et } \\
\text { al., 2016) }\end{array}$ & 2016 & $\begin{array}{l}\text { Web-based interventions for cardiovascular risk factor management in older } \\
\text { people }\end{array}$ & $57 / 57$ \\
\hline
\end{tabular}

$\left(^{*}\right)$ Number of RCT included in the review / Number of primary studies include in the review.

consider the experimental design based on randomized control trials (RCT) as an inclusion criteria, which means that all of their primary studies are RCT; ii) on the opposite side, five reviews (Fry and Neff, 2009; Ngo et al., 2009; Lieffers and Hanning, 2012; Bort-Roig, Gilson, Puig-Ribera, Contreras and Trost, 2014; Bardus et al., 2015) do not include RCT; and iii) the remainder reviews consider both RCT and non RCT in the experimental design of their primary studies.

The different technologies identified by the authors in all the included systematic reviews and meta-analysis were categorized into:

- General-purpose information technologies, including mobile communications (Fry and Neff, 2009; Bolle et al., 2015; Blackman et al. 2013; Geraedts et al., 2013; Buchholz, Wilbur, Ingram and Fogg, 2013; Foster et al., 2013; Buhi et al. 2013; Chen and Schulz, 2016), messaging (e.g. mail or chat) (Foster et al., 2013), 
Table 2. Scope of the applications

\begin{tabular}{ll}
\hline Scope & Reviews \\
\hline \multirow{2}{*}{ Physical Activity } & (Fry and Neff, 2009; Kennedy et al., 2012; Blackman et al. 2013; Geraedts et al., \\
& 2013; Buchholz et al., 2013; Foster et al., 2013; Bort-Roig et al., 2014; Mateo et al., \\
& 2015; Bert et al., 2014; Matthews et al., 2016; Beishuizen et al., 2016) \\
\hline \multirow{2}{*}{ Nutrition and Weight Management } & (Fry \& Neff, 2009; Ngo et al., 2009; Kelders et al., 2011; Lieffers and Hanning, \\
& 2012; Vegting et al., 2014; Mateo et al., 2015; Laranjo et al., 2014; Bardus et al., \\
& 2015; Bert et al., 2014) \\
\hline \multirow{2}{*}{ Health Education } & (Fox, 2009; Kennedy et al., 2012; Bolle et al., 2015; Buhi et al. 2013; Moorhead et \\
\hline Loneliness and Social Isolation & al., 2013; Laranjo et al., 2014; Bert et al., 2014; Shingleton and Palfai, 2016) \\
\hline Emergency Situations & (Chen and Schulz, 2016) \\
\hline
\end{tabular}

videoconference (Hawley-Hague, Boulton, Hall, Pfeiffer and Todd, 2014; Chen and Schulz, 2016), social media (Moorhead et al., 2013; Laranjo et al., 2014; Bardus et al., 2015), serious games (Kennedy et al., 2012; Hawley-Hague et al., 2014; Chen and Schulz, 2016), virtual reality (Chen and Schulz, 2016), and audio/video animations (Shingleton and Palfai, 2016).

- Special purpose applications, namely, computer-based applications (Fox, 2009), web-based applications (Ngo et al., 2009; Kelders et al. 2011; Kennedy et al., 2012; Lieffers and Hanning, 2012; Vegting et al., 2014; Hawley-Hague et al., 2014; Chen and Schulz, 2016; Beishuizen et al., 2016), and smartphone applications (Foster et al., 2013; Buhi et al. 2013; Bort-Roig et al., 2014; Laranjo et al., 2014; Bardus et al., 2015; Bert, Giacometti, Gualano and Siliquini, 2014; Matthews, Win, Oinas-Kukkonen and Freeman, 2016; Chen and Schulz, 2016).

- Smart homes (Kennedy et al., 2012; Hawley-Hague et al., 2014).

- Wearable devices (Buhi et al. 2013).

Widely used, technologies for ageing in place have been promoting healthy lifestyles, including physical activity, nutrition and weight management or health education (Table 2). According the results, the promotion of health lifestyles has gotten considerable more attention than the technologies for ageing in place designed to support other aspects of the daily living of community-dwelling older (i.e. loneliness and social isolation, or emergency situations).

\section{Physical Activity}

Physical activity affects health conditions and current recommendations advice older adults to regularly perform it. Therefore, there is an extensive body of research on technological solutions to promote home-based physical activity interventions, since remote interventions removes the barrier of transportation and promotes the integration of physical activity into daily life (Geraedts et al., 2013). Eleven of the included reviews consider the promotion of physical activity among the analysed behaviour change interventions (Fry and Neff, 2009; Kennedy et al., 2012; Blackman et al. 2013; Geraedts et al., 2013; Buchholz et al., 2013; Foster et al., 2013; Bort-Roig et al., 2014; Mateo et al., 2015; Bert et al., 2014; Matthews et al., 2016; Beishuizen et al., 2016).

To promote physical activity, mobile communications and smartphones are being commonly used, applying support strategies that typically involve 'pushing' periodic prompts (e.g. messages) to the participants from a central source (Fry and Neff, 2009; Blackman et al. 2013), physical activity measures (Bort-Roig et al., 2014) and remote feedback (Geraedts et al., 2013).

When reported as an outcome, physical activity is being measured through validated questionnaires (e.g. the Short Questionnaire Assessing Health-enhancing - SQUASH, the Baecke Physical Activity Questionnaire, and the comprehensive evaluation of the Minnesota Leisure Time Physical Activity Questionnaire), or quantitative measures (Vegting et al., 2014). Examples of quantitative measures are steps per day or minutes of weekly exercise (Southard, Southard and Nuckolls, 2003) that can be performed by different types of devices, namely pedometers, accelerometers, or sensing platforms (Blackman et al. 2013; Consolvo et al. 2008).

Technological applications appear to have positive effects on physical activity behaviours (Fry and Neff, 2009; Blackman et al. 2013; Foster et al., 2013; Bort-Roig et al., 2014; Mateo et al., 2015; Matthews et al., 2016), but the results are not consistent (Fry and Neff, 2009). For instance, a review (Blackman et al., 2013) reports that within the 14 RCT being analysed, six studies found that the intervention group had significant differences compared with the control group, four studies had mixed results, and another four had no significant differences between groups.

Furthermore, long-term, sustainable behaviour change and health benefits are not shown by the included reviews because of the lack of consistent follow-up data collection and reporting. 


\section{Nutrition and Weight Management}

Nine of the included reviews (Fry and Neff, 2009; Ngo et al., 2009; Kelders et al. 2011; Lieffers and Hanning, 2012; Vegting et al., 2014; Mateo et al., 2015; Laranjo et al., 2014; Bardus et al., 2015; Bert et al., 2014) deals with nutrition and weight management.

In terms of nutrition, two studies reported nutrition applications able to capture dietary intake (Ngo et al., 2009; Lieffers and Hanning, 2012) that can be divided into: i) applications that allow users to select food and portion size; ii) applications that process food photographs taken by the users; and iii) applications supporting questionnaires such as the Food Frequency Questionnaire (FFQ) or the MEDFICTS score (Vegting et al., 2014). Overall, it seems that the use of nutrition applications resulted in better self-monitoring adherence and changes in dietary intake when compared to conventional techniques (e.g. paper records) (Ngo et al., 2009; Lieffers and Hanning, 2012).

Concerning weight management, remote interventions are being delivered using a wide range of technologies, including web-based applications and smartphone applications, or even more traditional methods, such as telephone calls. The interventions can be delivered to groups or individuals, and they can involve one-off or ongoing interactions between the implementer and the participants that included: counselling or advice, selfdirected or prescribed exercise, home-based or facility based exercise, and written education or motivational support material, including the promotion of knowledge using serious games (Kennedy et al., 2012).

Regarding the outcomes, compared to control groups, most primary RCT studies of the included reviews pointed a significant net difference in weight between the interventions and control groups. This is valid for different types of technologies (e.g. web-based applications (Lieffers and Hanning, 2012)), but is particularly evident when mobile applications are being used (e.g. periodic prompts of a smartphone applications (Fry and Neff, 2009; Mateo et al., 2015)).

\section{Health Education}

Information technologies offer a medium to be used by the public, patients, and health professionals to communicate about health issues. This is a possibility of potentially improving health outcomes, through collaboration and social interaction mechanism (i.e. information exchange to promote knowledge, selfmanagement, perceived social support and health service utilization (Bolle et al., 2015)), which brings a new dimension to health care for a wide range of individuals.

Therefore, eight reviews reported the use of technologies for ageing in place for citizens' education (Fox, 2009; Kennedy et al., 2012; Bolle et al., 2015; Buhi et al. 2013; Moorhead et al., 2013; Laranjo et al., 2014; Bert et al., 2014; Shingleton and Palfai, 2016), covered a diverse population in terms of age, gender, education level, health status and healthcare intervention or disease state, and making use of different technologies, namely social media (e.g. Wiki, YouTube, Facebook, blogs, twitter and Myspace (Moorhead et al., 2013)) or personal health records to tailor personalized information.

Several outcomes related to knowledge gains, motivation, preventive behaviour, and reduced education staff costs for low risk patients were considered. Additionally, a review (Geraedts et al., 2013) report interactive education to support client self-monitoring of behaviour change progress in order to promote treatment and medication adherence, and two reviews target substance use behaviours (e.g. problem drinking or smoke cessation), using individualized programs (Vegting et al., 2014; Shingleton and Palfai, 2016).

The included reviews pointed that technologies for ageing in place are promising tools to facilitate immediate, intermediate and long-term health related outcomes in older adults by providing and exchanging information, and promoting self-management. This enables the provision of health information on a range of situations, facilitates the answers to medical questions, promotes the dialogue, allows the data collection on participants' experiences, enables more available, shared and tailored information, and, therefore, might increase accessibility, widen access, support public health surveillance, and inform health policies (Moorhead et al., 2013).

However, lack of reliability and quality metrics, together with the risks associated with harmful communication or incorrect answers using social media (Moorhead et al., 2013) are general concerns. Furthermore, future studies are required to achieve strong levels of evidence and designers of health behaviour interventions need to consider adequately the existing informatics methods and algorithms (Kennedy et al., 2012).

\section{Loneliness and Social Isolation}

Loneliness is a subjective concept related to a perceived absence or loss of companionship, always involuntary, while social isolation concerns the lack of structural and functional social support and can be either voluntary or involuntary (Dickens, Richards, Greaves and Campbell, 2011). Researchers report that the impact of social relationships on the risk of mortality is comparable with major, well-established risk factors such as smoking and alcohol consumption, and exceeds that of physical inactivity and obesity (Dickens et al., 2011; Holt-Lunstad, Smith and Layton, 2010). 
One of the included reviews (Chen and Schulz, 2016) analysed twenty-five primary studies related to the use of technological solutions to surpass social isolation. The intervention in all but two primary studies was implemented in the regular living environments of the participants.

Most studies used some form web-based or mobile applications. A minority of the studies was related to telephone befriending intervention, videogames and the use of a visual pet companion application that allowed the older adults to interact with an avatar in real time (Chen and Schulz, 2016).

Technologies for ageing in place were consistently found to affect social support, social connectedness, and social isolation in general positively. The results show that technological solutions can facilitate several mechanisms, including connecting to the outside world (e.g. family members, especially grandchildren, friends, former colleagues or new contacts of shared interests) and, mostly important, boosts self-confidence and empowerment, which trigger positive feelings of the participants and their control over life and/or life satisfaction (Chen and Schulz, 2016).

However, most studies measured the impact in social isolation through specific dimensions rather than social isolation in general. On the other hand, positive effect on social connectedness and social support seemed to be short-term and did not last for more than six months after the intervention, and the results related to loneliness were inconclusive. The generalizability of the results is limited since most primary studies tested the interventions as a one-time trial among a small number of participants (Chen and Schulz, 2016).

Therefore, although the potential impact of technologies for ageing in place might have in the promotion of social contacts, the included review (Chen and Schulz, 2016) suggest more well-designed studies on the effect the interventions and the identification of how the training and implementation of such intervention should be tailored to maximize its effect.

\section{Emergency Situations}

One review (Hawley-Hague et al., 2014) reports several exploratory, observational and feasibility studies to evaluate several types of technologies (e.g. personal alarms, home automation systems, video monitoring and smart technologies such as bed sensors, kitchen sensors, motion sensors or fall detection sensors) to help older adults to overcome emergency situations.

Older adults reported improved safety, independence and confidence, particularly when technologies with real time monitoring are connected to a response system (Hawley-Hague et al., 2014). However, there is still the lack of robust evidence. The results also show that applications aimed at predicting, monitoring and preventing should consider intrinsic factors related to older attitudes around control, independence and perceived requirements for safety. This is important for users' motivation to use and continue using technological solutions (e.g. qualitative research shows that participants were found to reject technology, as they did not want their home to look like a hospital (Blythe, Monk and Doughty, 2005)).

\section{DISCUSSION AND CONCLUSION}

Considering the first research question of the present study (i.e. which aspects of the daily living of communitydwelling older adults can be assisted by technologies for ageing in place?), two systematic reviews target loneliness and social isolation and emergency situations, while the remainder reviews target behaviour changing. Behaviour changing includes promotion of physical activity, nutrition and weight management, and health education.

Physical inactivity and obesity, smoking and alcohol consumption are well-established risk factors with impact in health conditions and mortality. Loneliness and social exclusion are generally understood as dramatic consequences of the social ageing and the response to emergency situations is generally accepted as an important issue for older adults. Therefore, the results of the present systematic review are in line with current concerns (Queirós, Carvalho, Pavão and Rocha, 2013).

In terms of what technologies for ageing in place have recently been used to assist community-dwelling older adults in their daily living (i.e. the second research question), the results show that there is a widespread use of general purpose information technologies (e.g. mobile communications, messaging, videoconference, social media, serious games, virtual reality or audio/video animations), and special purpose applications, including computerbased applications, web-based applications and smartphone applications. Additionally, two reviews report the use of smart homes and one review reports the application of wearable devices.

Some technologies have gotten more references than others. Particularly, mobile applications such as applications to deliver periodic prompts and reminders (Fry and Neff, 2009) were reported by a considerable number of articles. In this respect, the portability of smartphones enables users to have access 24 hours a day, making possible the long-term management and reinforcement of health behaviours through a variety of applications. This seems to promote the focus of the participants and their adherence to the programs. 
Finally, in what concerns the third research question of this study (i.e. what are the evidences of the adoption of technologies for ageing in place among community-dwelling older adults?) the analyses of the retrieved articles suggest that the use of technologies for ageing in place have positive effects with a moderate to large improvements in different outcomes when compared with conventional practices.

One of the problems that emerge from the study reported in the present article is related to the outcomes being measured. Besides their diversity, it is important to refer that different measurement methods are being applied. This is an important difficulty when aggregating and analysing data from different trials, which is essential to achieve the statistical and clinical significance that is required to promote the adoption of new services.

Despite the huge research effort related to technologies for ageing in place, there is insufficient evidence that successful interventions have been translated beyond the research setting and been broadly adopted. Potential reasons for this lack of translation should be deeply studied.

It should be acknowledged that this study has limitations related to the dependency on the keywords, the databases and the language selected (i.e. English), which means that there is a possibility that important studies were not identified.

However, it should also be pointed that this study presents some strengths. First, the methodological design was as elaborate as possible to guarantee that the review selection and the data extraction were rigorous. Secondly, the systematically collected evidence contributes to the understanding of the technologies for ageing in place to support community-dwelling older adults.

\section{ACKNOWLEDGMENT}

This work was partially supported by COMPETE - Programa Operacional Competitividade e Internacionalização (COMPETE 2020), Sistema de Incentivos à Investigação e Desenvolvimento Tecnológico (SI I\&DT), under the project Social Cooperation for Integrated Assisted Living (SOCIAL).

\section{REFERENCES}

Alvarez-Jimenez, M., Alcazar-Corcoles, M.A., González-Blanch, C., Bendall, S., McGorry, P.D. and Gleeson, J.F. (2014). Online, social media and mobile technologies for psychosis treatment: a systematic review on novel user-led interventions. Schizophrenia research, 156(1), pp. 96-106.

Arambepola, C., Ricci-Cabello, I., Manikavasagam, P., Roberts, N., French, D.P. and Farmer, A. (2016). The impact of automated brief messages promoting lifestyle changes delivered via mobile devices to people with type 2 diabetes: a systematic literature review and meta-analysis of controlled trials. Journal of medical Internet research, 18(4).

Bardus, M., Smith, J.R., Samaha, L. and Abraham, C. (2015). Mobile phone and web 2.0 technologies for weight management: A systematic scoping review. Journal of medical Internet research, 17(11).

Baron, J., McBain, H. and Newman, S. (2012). The impact of mobile monitoring technologies on glycosylated hemoglobin in diabetes: a systematic review. Journal of diabetes science and technology, 6(5), pp. 1185-1196.

Beishuizen, C.R., Stephan, B.C., van Gool, W.A., Brayne, C., Peters, R.J., Andrieu, S., ... and Richard, E. (2016). Web-Based interventions targeting cardiovascular risk factors in middle-aged and older people: a systematic review and meta-analysis. Journal of medical Internet research, 18(3).

Bert, F., Giacometti, M., Gualano, M.R. and Siliquini, R. (2014). Smartphones and health promotion: a review of the evidence. Journal of medical systems, 38(1), 1.

Blackman, K.C., Zoellner, J., Berrey, L.M., Alexander, R., Fanning, J., Hill, J.L. and Estabrooks, P.A. (2013). Assessing the internal and external validity of mobile health physical activity promotion interventions: a systematic literature review using the RE-AIM framework. Journal of medical Internet research, 15(10).

Blythe, M.A., Monk, A.F. and Doughty, K. (2005). Socially dependable design: The challenge of ageing populations for HCI. Interacting with Computers, 17(6), pp. 672-689.

Bolle, S., Van Weert, J.C., Daams, J.G., Loos, E.F., De Haes, H.C. and Smets, E.M. (2015). Online health information tool effectiveness for older patients: a systematic review of the literature. Journal of health communication, 20(9), pp. 1067-1083.

Bort-Roig, J., Gilson, N.D., Puig-Ribera, A., Contreras, R.S. and Trost, S.G. (2014). Measuring and influencing physical activity with smartphone technology: a systematic review. Sports Medicine, 44(5), 671.

Boulos, M.N.K., Brewer, A.C., Karimkhani, C., Buller, D.B. and Dellavalle, R.P. (2014). Mobile medical and health apps: state of the art, concerns, regulatory control and certification. Online journal of public health informatics, 5(3), 229. 
Buchholz, S.W., Wilbur, J., Ingram, D. and Fogg, L. (2013). Physical activity text messaging interventions in adults: a systematic review. Worldviens on Evidence-Based Nursing, 10(3), pp. 163-173.

Buhi, E.R., Trudnak, T.E., Martinasek, M.P., Oberne, A.B., Fuhrmann, H.J. and McDermott, R.J. (2013). Mobile phone-based behavioural interventions for health: A systematic review. Health Education Journal, 72(5), pp. 564583.

Camarinha-Matos, L. and Afsarmanesh, H. (2011). Collaborative ecosystems in ageing support. Adaptation and value creating collaborative networks, pp. 177-188.

Chen, Y.R.R. and Schulz, P.J. (2016). The effect of information communication technology interventions on reducing social isolation in the elderly: A systematic review. Journal of medical Internet research, 18(1).

Connelly, K., Mokhtari, M. and Falk, T.H. (2014). Approaches to understanding the impact of technologies for aging in place: a mini-review. Gerontology, 60(3), pp. 282-288.

Consolvo, S., Klasnja, P., McDonald, D.W., Avrahami, D., Froehlich, J., LeGrand, L., ... and Landay, J.A. (2008, September). Flowers or a robot army?: encouraging awareness \& activity with personal, mobile displays. In Proceedings of the 10th international conference on Ubiquitous computing (pp. 54-63). ACM.

Conway, A., Inglis, S.C. and Clark, R.A. (2014). Effective technologies for noninvasive remote monitoring in heart failure. Telemedicine and e-Health, 20(6), pp. 531-538.

Davis, T.L., DiClemente, R. and Prietula, M. (2016). Taking mHealth forward: examining the core characteristics. JMIR $m$ Health and $u$ Health, 4(3).

Dickens, A.P., Richards, S.H., Greaves, C.J. and Campbell, J.L. (2011). Interventions targeting social isolation in older people: a systematic review. BMC public health, 11(1), 647.

El-Gayar, O., Timsina, P., Nawar, N. and Eid, W. (2013). A systematic review of IT for diabetes self-management: are we there yet?. International journal of medical informatics, 82(8), pp. 637-652.

Emery, D., Heyes, B.J. and Cowan, A.M. (2002). Telecare delivery of health and social care information. Health Informatics Journal, 8(1), pp. 29-33.

Eysenbach, G. (2008). Medicine 2.0: social networking, collaboration, participation, apomediation, and openness. Journal of medical Internet research, 10(3).

Farmer, A.J., McSharry, J., Rowbotham, S., McGowan, L., Ricci-Cabello, I. and French, D.P. (2016). Effects of interventions promoting monitoring of medication use and brief messaging on medication adherence for people with type 2 diabetes: a systematic review of randomized trials. Diabetic Medicine, 33(5), pp. 565-579.

Foster, C., Richards, J., Thorogood, M. and Hillsdon, M. (2013). Remote and web 2.0 interventions for promoting physical activity. Cochrane Database Syst Rev, 9(9).

Fox, M.P. (2009). A systematic review of the literature reporting on studies that examined the impact of interactive, computer-based patient education programs. Patient education and counseling, 77(1), pp. 6-13.

Fry, J.P. and Neff, R.A. (2009). Periodic prompts and reminders in health promotion and health behavior interventions: systematic review. Journal of medical Internet research, 11(2).

Garabedian, L.F., Ross-Degnan, D. and Wharam, J.F. (2015). Mobile Phone and Smartphone Technologies for Diabetes Care and Self-Management. Current diabetes reports, 15(12), pp. 109-109.

Garcia Vazquez, M.Y., Ferras Sexto, C., Rocha, Á. and Aguilera, A. (2016). Mobile phones and psychosocial therapies with vulnerable people: A first state of the art. Journal of Medical Systems, 40(6), pp. 1-12.

García-Lizana, F. and Muño-Mayorga, I. (2010). Telemedicine for depression: a systematic review. Perspectives in Psychiatric Care, 46(2), pp. 119-126.

Geraedts, H., Zijlstra, A., Bulstra, S.K., Stevens, M. and Zijlstra, W. (2013). Effects of remote feedback in homebased physical activity interventions for older adults: a systematic review. Patient education and counseling, 91(1), pp. 14-24.

Ghapanchi, A.H. and Aurum, A. (2011). Antecedents to IT personnel's intentions to leave: A systematic literature review. Journal of Systems and Software, 84(2), pp. 238-249.

Groen, W.G., Kuijpers, W., Oldenburg, H.S., Wouters, M.W., Aaronson, N.K. and van Harten, W.H. (2015). Empowerment of cancer survivors through information technology: an integrative review. Journal of medical Internet research, 17(11).

Hawley-Hague, H., Boulton, E., Hall, A., Pfeiffer, K. and Todd, C. (2014). Older adults' perceptions of technologies aimed at falls prevention, detection or monitoring: a systematic review. International journal of medical informatics, 83(6), pp. 416-426.

Highton-Williamson, E., Priebe, S. and Giacco, D. (2015). Online social networking in people with psychosis: A systematic review. International Journal of Social Psychiatry, 61(1), pp. 92-101.

Holt-Lunstad, J., Smith, T.B. and Layton, J.B. (2010). Social relationships and mortality risk: a meta-analytic review. PLoS medicine, 7(7), e1000316. 
Kelders, S.M., Kok, R.N. and Van Gemert-Pijnen, J.E. (2011, June). Technology and adherence in web-based interventions for weight control: a systematic review. In Proceedings of the 6th International Conference on Persuasive Technology: Persuasive Technology and Design: Enhancing Sustainability and Health (p. 3). ACM.

Kennedy, C.M., Powell, J., Payne, T.H., Ainsworth, J., Boyd, A. and Buchan, I. (2012). Active assistance technology for health-related behavior change: an interdisciplinary review. Journal of medical Internet research, 14(3).

Kruse, A. (2012). Active ageing: solidarity and responsibility in an ageing society. Centre for European Studies. Belgium: Drukkerij Jo Vandenbulcke.

Kvedar, J., Coye, M.J. and Everett, W. (2014). Connected health: a review of technologies and strategies to improve patient care with telemedicine and telehealth. Health Affairs, 33(2), pp. 194-199.

Laranjo, L., Arguel, A., Neves, A.L., Gallagher, A.M., Kaplan, R., Mortimer, N., ... and Lau, A.Y. (2014). The influence of social networking sites on health behavior change: a systematic review and meta-analysis. Journal of the American Medical Informatics Association, 22(1), pp. 243-256.

Lazar, A., Thompson, H. and Demiris, G. (2014). A systematic review of the use of technology for reminiscence therapy. Health education \& behavior, 41(1_suppl), pp. 51S-61S.

Lieffers, J.R. and Hanning, R.M. (2012). Dietary assessment and self-monitoring: With nutrition applications for mobile devices. Canadian Journal of Dietetic Practice and Research, 73(3), pp. e253-e260.

Lundell, S., Holmner, Å., Rehn, B., Nyberg, A. and Wadell, K. (2015). Telehealthcare in COPD: a systematic review and meta-analysis on physical outcomes and dyspnea. Respiratory medicine, 109(1), pp. 11-26.

Mateo, G.F., Granado-Font, E., Ferré-Grau, C. and Montaña-Carreras, X. (2015). Mobile phone apps to promote weight loss and increase physical activity: a systematic review and meta-analysis. Journal of medical Internet research, 17(11).

Matthews, J., Win, K.T., Oinas-Kukkonen, H. and Freeman, M. (2016). Persuasive technology in mobile applications promoting physical activity: a systematic review. Journal of medical systems, 40(3), 1.

Moorhead, S.A., Hazlett, D.E., Harrison, L., Carroll, J.K., Irwin, A. and Hoving, C. (2013). A new dimension of health care: systematic review of the uses, benefits, and limitations of social media for health communication. Journal of medical Internet research, 15(4).

Mori, A.R., Mazzeo, M., Mercurio, G. and Verbicaro, R. (2013). Holistic health: predicting our data future (from inter-operability among systems to co-operability among people). International journal of medical informatics, 82(4), pp. e14-e28.

Nakamura, N., Koga, T. and Iseki, H. (2014). A meta-analysis of remote patient monitoring for chronic heart failure patients. Journal of telemedicine and telecare, 20(1), pp. 11-17.

Ngo, J., Engelen, A., Molag, M., Roesle, J., García-Segovia, P. and Serra-Majem, L. (2009). A review of the use of information and communication technologies for dietary assessment. British Journal of Nutrition, 101(S2), pp. S102-S112.

Normie, L. (2011). Technology for ageing in place. IFA (International Federation on Ageing) Global Ageing, 7(2), pp. 45-53.

Norris, A.C. (2001). The strategic support of telemedicine and telecare. Health Informatics Journal, 7(2), pp. 8189.

Or, C.K. and Tao, D. (2014). Does the use of consumer health information technology improve outcomes in the patient self-management of diabetes? A meta-analysis and narrative review of randomized controlled trials. International journal of medical informatics, 83(5), pp. 320-329.

Pastalan, L.A. (1990). Aging in place: The role of housing and social supports. Psychology Press.

Pedone, C. and Lelli, D. (2015). Systematic review of telemonitoring in COPD: an update. Advances in Respiratory Medicine, 83(6), pp. 476-484.

Queirós, A., Carvalho, S., Pavão, J. and da Rocha, N.P. (2013). AAL Information based Services and Care Integration. In HEALTHINF (pp. 403-406).

Queirós, A., Pereira, L., Dias, A. and da Rocha, N.P. (2017, February). Technologies for Ageing in Place to Support Home Monitoring of Patients with Chronic Diseases. In HEALTHINF (pp. 66-76).

Queirós, A., Pereira, L., Santos, M. and Rocha, N.P. (2017, April). Technologies for Ageing in Place to Support the Empowerment of Patients with Chronic Diseases. In World Conference on Information Systems and Technologies (pp. 795-804). Springer, Cham.

Queirós, A., Santos, M., Cerqueira, M. and Rocha, N.P (2017). Technologies for Ageing in Place to Support Community-Dwelling Older Adults. In 12th Iberian Conference on Information Systems and Technologies (CISTI), 2017 (pp. 1460-1465). AISTI.

Richards, D. and Richardson, T. (2012). Computer-based psychological treatments for depression: a systematic review and meta-analysis. Clinical psychology review, 32(4), pp. 329-342.

Rigby, M. (2012). Integrating health and social care informatics to enable holistic health care. Stud Health Technol Inform, 177, pp. 41-51. 
Salvador-Carulla, L. and Gasca, V.I. (2010). Defining disability, functioning, autonomy and dependency in personcentered medicine and integrated care. International Journal of Integrated Care, 10(5), e025.

Sharp, I.R., Kobak, K.A. and Osman, D.A. (2011). The use of videoconferencing with patients with psychosis: a review of the literature. Annals of general psychiatry, 10(1), 14.

Shingleton, R.M. and Palfai, T.P. (2016). Technology-delivered adaptations of motivational interviewing for healthrelated behaviors: A systematic review of the current research. Patient education and counseling, 99(1), pp. 17-35.

Southard, B.H., Southard, D.R. and Nuckolls, J. (2003). Clinical trial of an Internet-based case management system for secondary prevention of heart disease. Journal of Cardiopulmonary Rehabilitation and Prevention, 23(5), pp. 341348.

Vegting, I.L., Schrijver, E.J.M., Otten, R.H.J. and Nanayakkara, P.W.B. (2014). Internet programs targeting multiple lifestyle interventions in primary and secondary care are not superior to usual care alone in improving cardiovascular risk profile: a systematic review. European journal of internal medicine, 25(1), pp. 73-81.

World Health Organization (WHO) (2004). A glossary of terms for community health care and services for older persons. Technical Report, vol. 5, Centre for Health Development Ageing and Health. Kobe: WHO Press. 